\title{
Meditations on memory
}

\author{
Heather Home \\ Queen's University
}

\begin{abstract}
Archives have often been thought of as the warehouses of collective or societal memory. This article explores the role of memory, in both its physical and metaphysical state, in the field of archival study. The functionality of individual human memory is investigated in order to understand how it operates and becomes co-opted into an institutional archival setting. Since it is the archivist's goal to reflect and collect societal memory through the documentary heritage of the populace, it is therefore important for archivists to be aware of the way in which memory functions within the individuals who make up that population.
\end{abstract}

Keywords: collective memory; archives and memory; documentary heritage; warehouse of collective memory

RÉSUMÉ

Il est possible d'imaginer des archives aux entrepôts de la mémoire collective de la société. Cet article explore le rôle de la mémoire, dans sons état physique et métaphysique, dans le domaine des archives. La fonction de la mémoire des individues est examinée pour mieux comprendre son intégration dans les archives. Puisque le but de l'archiviste est de rassembler l'héritage documentaire de la mémoire collective, il est donc important que les archivistes se rendent compte de la fonction de la mémoire de chaque personne.

Mots-cléfs: mémoire collective, archives et mémoire, héritage documentaire, entrepôts de la mémoire collective

\section{RESUMEN}

A menudo se piensa que los archivos son depósitos de la memoria colectiva de la sociedad. Este artículo explora el papel de la memoria, en su estado físico y metafísico, en el campo de los estudios de archivos. La funcionalidad de la memoria humana individual es investigada con la finalidad de entender el proceso de integración de la memoria en un archivo institucional. Dado que el objetivo del archivista es reflejar y coleccionar la memoria de la sociedad a través de la herencia documental de la población, es importante que los archivistas presten atención a la manera en que la memoria funciona en la vida de los individuos que forman la población.

Descriptores: memoria colectiva; archivos y memoria; herencia documental; depósito de memoria 
... a good memory is about one-third cure and two-thirds curse. That boy's brain was a savings account with waste in it. True facts had snagged and abscessed, their sharp ends in. His poor young head was a pincushion calendar. If they made my husband walk through one of these new aeroport $\mathrm{X}$-ray machines checking for weaponry? why, just his memory would set it off. (Allen Gurganus, Oldest Living Confederate Widow Tells All.)

\section{Introduction}

What is memory? Is it more curse than cure, as Gurganus suggests, or the other way around? Societal memory, as represented in archival institutions, is widely regarded as a cure-holding the solutions to so many unanswered, and some as yet unasked, questions. The image of archivists as keepers of the past is pervasive, but unlike the mind of Gurganus' boy, archives are thought not to retain any waste or debris, but rather to hold the products and riches of society's documentary heritage. Is this truly the function of archives, to be a cure, healing the partial or incomplete memory of the past, amassing and attending to all those snagged and abscessed bits and thus creating a cohesive whole? Many archives are so mandated, and seek to retain this unified whole, comprising the social or collective memories of the cultures in which they participate. It is proposed that formation of this broader collective memory of society does not differ vastly from memories retained by individuals and that much can be learned through a study of the relationship of these processes.

According to some sociological research, collective memory "refers to beliefs and ideas held in common by many individuals that together produce a sense of solidarity and community."' There exists no collective memory without reference to a socially specific framework, "collective memory, then, the memory of culture, depends upon systems of representation and systems of representatives." This system of acknowledged and agreed upon representatives functioning within a specific framework is commonly known as society. This notion of society

has continued to be used to designate a fundamental category of human existence... [but] only in space and time does society become concrete reality, for every society necessarily possesses a structure which orders the coexistence of individuals. $^{3}$

Therefore, society is not only made up of the individuals who participate in it, but also the systems of order in which they operate and are governed.

Social theorist Maurice Halbwachs, rejects any difference between the manner in which an individual preserves and recollects memories and the manner in which a society performs the same tasks. Halbwachs contends that the notion of individual memory unconnected to the social or collective memory is an abstraction without meaning. Memory is not the mere recollection of events but the evocation of their meaning. Any attempt to examine these memories, without the social context in 
which they occurred and were retained is destined to rob them of the potential meaning they may communicate to others. It is only through membership within a social group that an individual is capable of obtaining, localizing and recalling memories. It appears that

every recollection, however personal it may be, even that of events which we alone were the witnesses, even that of thoughts and sentiments that remain unexpressed, exists in relationship with a whole ensemble of notions which many others possess; which persons, places, dates, words, forms of language, that is to say with the whole material and moral life of the societies of which we are part or of which we have been part. ${ }^{4}$

The concept of collective memory, however, is not merely individual memory metamorphosed. There are other factors involved. The most prominent of these is the act of transcription. Jack Goody has written in The Interface Between the Written and the Oral that "although many factors were involved in the rise of early civilizations, the beginning of complex social organization seemed to require a means of notating the spoken word." 5 Therefore the written word, as well as aiding in the establishment of societal culture, allows for its perpetuation over time. Mark Kingwell states, "Writing on paper, using ink ... is defined by its grapple with time. Writing works because the setting down of ideas also means the taking up of them again later, at some future date as yet undetermined."6

Societies and cultures create and are created by collective memory, a system of beliefs common to all; systems of communal practice and communication are common to all groups of animals, including humans. In comparing the differences and similarities of memory among species, Steven Rose has surmised that "all living species have a past, [but] only humans have a history." This history, which is particular to humans, is based on what Rose calls "artificial memory", a memory based on the written word. The transcription of memory to a tangible medium is the act that creates history and which plays an integral part in the formation of a society's collective memory. Rose refers to this memory as "artificial" because, once affixed to a medium, memory no longer retains what he considers to be fundamental: the ability to be flexible and alterable. Whether this type of memory is considered to be artificial (which may carry negative connotations) or not, it does provide the basis through which society is able to communicate over an extended temporal and spatial range. The written word connects the memory of individuals to that of the larger societal system in which they participate.

To understand the role that collective or societal memory plays in the field of archival study, it is worthwhile to examine the way in which memory functions in the individual, for formation of memory in the individual is the basis on which memory is employed on the larger scale. In terms of societal memory and history, individual memory may become both amplified and diluted in its application to this grander framework. By examining both the distortions and consistencies which occur in this 
conceptual expansion our understanding of the archival project to manage and participate in societal memory may improve.

\section{Aspects of Memory}

In an individual, there are different aspects of memory, but our focus here is the idea of conscious memory. Conscious memory, as defined by Mary Warnock, is the

kind of memory that must be thought of as mental, not physical, for it must be experienced, and experienced privately, within the mind of each of us ... [the] capacity, which is consciously to reflect on their lives and histories. Memoryexperiences are what we [are] interested in, and having learned a skill is not an experience. $^{8}$

Conscious memory tends to provide the commentary that is essential to perceiving the past in a manner that can be understood. It is through conscious memory that the meaning behind an action or experience is articulated. It is this characteristic of memory that is uniquely human.

Conscious memory, however, does not function independently. It works in collaboration with what has been termed, "habit memory." Habit memory is the ability to learn and remember skills that are habitually utilized in everyday life. According to Warnock, this collaboration between conscious and habit memory should be thought of as a "continuum," with consciousness being located at one end; neither form of memory is exclusive from the other.

Conscious memory is that form of memory involved in the creation of individual identity. Due to the fragmented nature of individual existence in the modern world, individuals find themselves disassociated from conventional juridical ties such as family or locale. In this environment, identity has been rendered a variable. To this end, the role of conscious memory is particularly relevant as, "people find themselves engaged in self-designation, for [conscious memory] serves as a stabilizer of, and justification for, the self-designations that people claim."9 Shaped by conscious mind and memory, identity can be perceived as a matter of individual choice, reflecting how individuals wish to be designated within the larger social system. Conscious memory serves as a support mechanism for the foundation of an identity which otherwise may seem unfounded.

It is with the advent of writing that the textual embodiment of a shared memory, external to the mind of an individual, is realised. With this comprehension, documents are integral to the survival of memory, carrying it forward for scrutiny by contemporary society. It is as the keepers of these records and documents that archivists have come to be thought of as key participants in the perpetuation of collective memory.

The archival pursuit of preserving collective memory, in its documentary form, is analogous to the concerns of the conscious memory of the individual. In archival theory, the concept of memory-experiences translates into a concern with preserving records of action. Archival documents are those which are created, received and used 
by an organization or person in the course of its practical actions, and preserved as evidence of its mandate, functions and activities. ${ }^{10}$ This need not be as clinical as it sounds. This evidence can be as pedestrian as the documentary by-products of everyday living. By preserving the documentary traces of the actions of juridical or physical individuals, archival institutions attempt to preserve and represent the larger collective memory of society.

Also of concern to archives are the patterns and intricacies of procedure and process which result in these memory-experiences (i.e. actions). For it is through procedure and process, in current society, that action is taken. The processes and procedures that guide action, be it individual or organizational, play an integral part in the identification of that body to the larger community in which it exists. So, very much like the memory of the individual, the memory of the past that is retained in the archives should ideally be based on the collaboration of both conscious and habit memory, forming a continuum of past events. Archival documents should reveal the representation and meaning of the socio-communal environment in which they were created. Contemporary archival practice and theory attempts to maintain this environment "by placing the recorded traces of individuals, groups, continuities, events and forces in the interactive context of their creative formulation." ${ }^{11}$ In attempting to retain the context of creation, archivists have a greater chance of securing the documentary essence and elemental consciousness of society and its connections.

In their role as a warehouse of the collective memory of society, and through the preservation of both conscious and habit memory, archives also participate as an agent in the designation of identity. As a result of the tasks performed within archives (as well as other cultural institutions), society as a whole comes to an understanding of its past, creating a sense of collective identity. It would be a simplification to state that society comes to know itself merely through its memory, for it is indeed a reciprocal arrangement between the systems of representation and the transcribed objects of representation that is involved in the creation or acceptance of identity. As Halbwachs has stated,

social identities in question already have a determinate existence before the collective memories that, at every moment, they construct ... [however] over time identity will undoubtedly be reshaped by the collective memories that it has constructed. ${ }^{12}$

Individual memory feeds the collective memory, but in turn becomes shaped by it. And as identification with family and locale has weakened, due to the reduction in the size and function of each, the construct of collective or societal memory as a form of nationalism has become more prevalent. Archives and cultural institutions are often created in order to construct a sense of belonging, a sense of a shared past, a feeling of patriotism. It is through this interpretation of a shared past that the individual finds a place in the present, giving rise to a national identity and memory. In this discussion, the concept of collective memory can be seen as synonymous with national memory. The notion of national identity is made up of individuals "who define themselves 
increasingly in terms of a broadened, national community, however amorphous, abstract and oxymoronic that concept may be." 13 Larger archival institutions are often under the obligation, as a result of their mandate or formulation, to document the history of the society of individuals and groups who function within their borders. This is not to say that there is one collective memory for the entirety of the nation, for within any national culture there exist a multitude of juridical systems, many of which stretch beyond national borders. In the context of individual nation-states, these smaller juridical systems can be delineated by an individual's self-identification within religious, economic and political belief systems. As with individual memories, these systems shape, and are shaped by, the collective memory of other juridical systems.

In Canada, the role of archives in the perpetuation and establishment of the collective identity has its origins in the establishment of its national archival institution. The mandate of the Public Archives of Canada was dedicated

to the end that a broad national spirit should prevail in all parts of the Dominion... that a sound knowledge of Canada as a whole, of its history, traditions and standards of life should be diffused among its citizens. ${ }^{14}$

Within this sense of collective national identity, based on national memory, there exist the many juridical societies that make up the jurisdiction that is bound together through the arbitrary constructions of the nation-state. The original goal of the Public Archives of Canada was to document the national memory through the inclusion of the smaller juridical societies, to document all aspects of historical development "not just of officialdom or of a governing elite but of all segments of a community." 15 The ideal of inclusivity of all of society has proven difficult to attain/maintain. Archival institutions, and the collective memory they foster, are subject to the same fragmentations and inconsistencies that plague individual memory.

\section{Memory and the Present}

Conscious memory in the individual is inherently tied to the present; it is a construction formulated in the present which then looks back upon the past. It is commonly an impetus within an individual's present position that draws them back, that provokes memory. Through either a purposeful, wilful recollection of the past based on a need to know, or through an unconscious yearning for stimulus, memory is evoked in the mind of an individual that is firmly rooted in the present. As much as memory has been likened to time travel, it is not capable of this leap. It is merely a directed gaze with reality firmly established in the present. Therefore, the essence of memory is twofold; there is the present idea, and the relation of this idea to the past. In How Societies Remember Paul Connerton states that there is

difficulty extracting our past from our present: not simply because present factors tend to influence-some might want to say distort-our recollections of 
the past, but also because past factors tend to influence, or distort, our experience of the present. ${ }^{16}$

The present, as well as being responsible for the remembrance of an occurrence, affects the manner and practice in which the past is regarded. An episode in our memory is related to events that came before it and ones which have occurred since. The effect of the present on memory is qualified by what is known about the functionality of the brain; memories come to the individual encoded by neural networks in the brain whose connections have already been shaped by previous experiences in the world. Therefore the past can never be looked back upon in any passive manner; it is modified and filtered through the present consciousness and functionality of the mind.

According to Dr. W. Walter Menninger, memory "can rarely be depended upon to faithfully recall past events, especially those in which the subject directly participated." ${ }^{17}$ Distortion in the case of individual memory is usually linked to the manner in which subjects currently view themselves. Individuals have other emotional qualifiers which often alter their ability to look back at past events without the intrusion of their present consciousness. Emotive characteristics such as pride, vanity, shame and fear may all come into play when memory is evoked.

In response to these characteristics the mind has the ability to alter past situations before they reach the forefront of our consciousness. This ability to alter memory is usually performed unconsciously and is therefore not equivalent to lying or purposely obscuring the truth. However, in an effort directed towards self-preservation and self-perception, consciousness will often mediate what we recall. Sometimes, when presented with a threat to this protective system, individuals are

reluctant to accept the idea that there exist within our minds thoughts, feelings, memories and past experiences which are not accessible to our conscious awareness, but which, nonetheless, influence our behaviour and conscious thoughts. ${ }^{18}$

Individuals are reluctant to accept the idea of self-deception, particularly given the value placed on truth and honesty.

In documenting the collective memories of established juridical systems, such as nations, archives are also constrained by the temporal and spatial dimension in which they exist. The role of the present, as with the memory of the individual, exerts a force on the manner in which archives acquire and preserve the memories of the past. In the I970's, Howard Zinn chastised archivists for "neglecting to collect records documenting significant social minorities outside the mainstream of American life." ${ }^{19}$ He made these accusations with the benefit of hindsight and, indeed, these remarks could only be made in retrospect, with a present awareness of contemporary fields of study and academic pursuit. With the gift of hindsight, these proclamations are justifiable, but archivists are not clairvoyant and yet must still deal with these issues. It is generally agreed by the archival community that 
Little can be done... to anticipate future research trends that alter the questions asked of the use of the documentation. Did archivists anticipate quantitative history, social history, women's history? No, these all represented new ways of thinking both for historical researchers and for archivists. ${ }^{20}$

The manner in which society views itself over time will change. This will likely be a result of the way in which society has chosen to view itself, but it will also be a result of the way in which archives and other cultural institutions have chosen to represent the past. Factors and issues of importance will change, and be altered, as the components of the juridical systems in which the archives operate, acquire and discard new characteristics of identity. Archivists have come to realize that the present, and their participation within it, influences how a society remembers its past. Brien Brothman states that

Archives do not live in a hermetic isolation from the rest of the world, for they do not transcend the social and cultural forces that have shaped our modern information-hungry, knowledge-based society; they, too, are positioned within-determined by-the web of information production, exchange and circulation. $^{21}$

The recognition that archivists too, are subjective beings, operating within a sociopolitical framework is reassurance that archivists and archives are in touch with the current trends of cultural thought that exist in the collective consciousness surrounding them. However, in the past, this same recognition of unavoidable bias on the part of archivists and archives has been identified as an undesirable quality; a quality best avoided by strict adherence to proper objective practice. In Terry Eastwood's discussion of early archival theory, he states that "Appraisal [as] an objective process of the acquisition and selection of objective things which may very well be put to interpretive use may be doubted." 22 Archival theory has developed an appreciation for the problems associated with stepping outside the bounds of individual and/or collective memory in order to participate in its creation. What are the possibilities, then, for archivists to distance themselves as individuals and yet connect on a collective level with the current spatial and temporal dimension? How are archivists to keep abreast of the changing characteristics of the collective memory and identity of the nation without becoming personally involved? There are a number of suggested theories to remedy this situation, but none appear to account for all of the possible ramifications that result from their practice. In the final analysis, the best practice that archives can currently employ is to listen to the records, and to the juridical and physical bodies which create them, the systems in which they were created, and to interpret what they hear.

\section{Memory, Imagination and Truth}

Memory is linked to the present, and stems from some form of stimulus located in the realm of the here and now. Memory is not the act of thinking about events as they 
happen but from a vantage point outside of their immediate timeframe. Memory is an act of reflection and recall, the thinking about things in their absence. Another act that is linked to consciousness, in this same manner, is imagination. Imagination is "the act or power of forming a mental picture of something not present to the senses; a creation of the mind" 23 : imagination is a representation. How closely connected are these two conscious abilities if they essentially manifest themselves through similar actions? And how do we distinguish between them?

Although defined as separate acts or abilities, imagination and memory are often incorporated with each other. Mary Warnock states

The images of memory become very like those of imagination and the one may imperceptibly shade off into the other, moving from what it was like to what it might have been like. ${ }^{24}$

Memory often functions as the filter through which individuals are able to recall episodes in a manner which they find more in tune with how they would have liked it to be. As stated earlier, this editing of the past usually takes place without intentional will or malice, but as a function of the subconscious mind. The past cannot be changed for it has indeed occurred; the individual's view of that past, however, can be manipulated: it is flexible within a certain framework.

There is a great deal of structure and formality beneath the surface of an individual's seamless recollection of the episodes and occurrences of their past. ${ }^{25}$ Memories often appear, or are referred to, in terms of visual imagery but they are not akin to a recorded tape of the event. Factors such as age, ability to understand, expectations and knowledge at the time of the event, as well as any number of physiological elements, can all play a role in the manner in which the past is remembered. Given the complexity and range of factors involved in the act of remembering, there exist a large number of possibilities for the memory to be manipulated or altered. When a memory is evoked it is not merely being replayed in our mind's eye, it is in fact being reinterpreted and reconstructed. In Searching for Memory: The Brain, the Mind and the Past, Daniel L. Schacter states that

we know enough about how memories are stored and retrieved to demolish [the] long-standing myth that memories are passive or literal recordings of reality ... but rather hold onto the meaning, sense and emotions these experiences provided us. ${ }^{26}$

Therefore, recollection appears to entail the intermingling of both imagination (with perhaps additions or deletions of characteristics of the occurrence) and memory which is linked to a specific past event that was physically witnessed. Memory is made up of recollection and repetition, and in repetition, memory is not transmitted intact, it undergoes continual revision.

The connections between memory and imagination are clear, but what are the differences that separate these concepts? The scholarly distinctions that have been made 
between these two mental processes are philosophical; there are no empirical methods by which to measure any quantitative difference between them. The most consistently defined characteristic, which has been marked as the key to understanding the distinction, is the "feeling of pastness." ${ }^{27}$ It is only with memory that there exists a given order, position and weight to the memory-experiences of the conscious mind. Given the intangible nature of this argument it is difficult to come up with more of a definitive statement than "because we know." ${ }^{8}$ We know the difference between fact and fiction; we know the difference between knowledge and belief; therefore we know the difference between memory and imagination. This knowledge however, is reserved for the individual remembrancer; it cannot be transmitted over time, or through the written word, to another party.

So why is the distinction between imagination and memory so important? The importance of being able to distinguish between these two exercises of the mind lies in the devotion to the ideal of truth. If it were not for this desire to unveil what is true and what is not, the concern for a distinction between memory and imagination would be devoid of meaning. If memory is, as some have observed, "a record of present beliefs and wishes, not a replica of the past [but] a reconstruction using bits of past experience to describe a present state," ${ }^{29}$ where can the veracity of the past be located and how is it to be obtained?

For some, the establishment of the truth of memory is an unnecessary, impossible and futile action. Memory in its healthy state serves the individual well. It allows for the recollection of experiences in accordance with an individual's perceptions of their own identity. It is "true" in the sense that it verifies what they perceive of themselves and the world around them. Toni Morrison, an author well known for her use of memory and memoir in her fiction, states that

memory (the deliberate act of remembering) is a form of willed creation. It is not an effort to find out the way it really was-The point is to dwell on the way it appeared and why it appeared in that way. ${ }^{30}$

The truth of memory only becomes an important issue when individual memories are to be passed on and communicated to others for the purpose of longer-term preservation. At that point, individual memories, formerly subject to the permutations and combinations of mental processes now become locked into a final edition, without further revision. It is at this point that memory takes on its social or collective dimension in addition to being centred on the individual. The most common form of present day communication over a spatial and temporal dimension is through transcription. Once memory has been transposed into script, it is no longer a fluid or flexible exercise, in effect, it has made time stand still. Memory dons a new mantle and becomes associated with stability.

With the mantle of stability draped upon it, memory becomes a tangible history, open to exploration and interpretation and, therefore, inconsistency. Truth comes into question when memory, or memoir (upon transcription), is utilised in the pursuit of history for the construction, reconstruction, or deconstruction of the past. 
If the exercises of memory and imagination have been shown to overlap, to what degree does the collective memory of society, which is kept by archives, reflect the truth of the past? Truth, as a characteristic of individual memory, is not a pertinent issue, yet with the documentary traces contained in archives, it can become a contentious one. The problem exists not for archivists, per se, but for a segment of their clientele, the historians. From the instance that the

discipline [of] history has existed, documents have been used, questioned and have given rise to questions; scholars have asked not only what these documents meant, but also whether they were telling the truth. ${ }^{31}$

Archives play an important role in answering this question, as both a place in which documentary evidence of the past is deposited, and a place on which the truth of history has come to depend. Archival documents have always received a greater weight and value when compared to other more accessible and widely disseminated records. As Keith Jenkins explains

If you refer to these sources as primary and if you sometimes replace primary by original (original and thus underlying/fundamental source), this suggests that if you go to the originals, then because originals seems genuine (as opposed to secondary/second-hand traces), genuine (true/ deep) knowledge can be gained. This prioritises the original source [and] fetishises documents. ${ }^{32}$

Original documents are therefore imbued with greater truth-value than other documents. Whether one is in agreement with this statement or not, it is important to understand that this status has been conferred upon the document not by the archivist, but by historians.

Archivists and archives have been particularly careful not to make claims ensuring the truth of the content of the record. It is the authenticity of the archival document that archives maintain, not the truth of its content. The archival definition of an authentic record is that the record is what it purports to be. Although it does not speak to the truth of a document's content, authenticity assigns truth-value to the document itself. This assignation of authenticity to the document can, and does, spill over to the content of the record, and lends credence to the establishment or supposition of truth. In conferring authenticity on the archival document, archives endow the document with a greater degree of authority than it possessed prior to its inclusion in the official collective memory (i.e. the repository). As Heather MacNeil has stated

To declare a document authentic was equivalent to saying that the document was recognized as true by the juridical system in which it was created... [therefore] a records' legal truth was considered a sufficient guarantee of its historical truth. ${ }^{33}$ 
Archival theory recognizes that the documents may speak to a truth but it also realises that the testimony of fact, to which archival documents attest, is not beyond distortion. Archival documents can be used to verify suppositions and interpretations that are already in place previous to their consultation. The documentary heritage is meant to reveal the way in which the records were used within the system in which they were created; the documentary heritage is not solely meant to verify the truth of past actions represented or discussed by the archival document. Documentary evidence is not

an inert material through which [history] tries to reconstitute what men have done or said... history is now trying to define within the documentary material itself, the unities, totalities, series, [and] relations. ${ }^{34}$

To this end, archival theory relies on concepts like original order and the principle of provenance. Original order, the interrelatedness of the records, and the archival bond are all key archival concepts which are founded in the belief that the manner in which the records are perceived and preserved is directly related to the records' relationship vis-à-vis each other. Archivists recognize that the construction of the fonds, series or record group should reflect the nature of the original purpose and process by which the records were created.

Archival theory clearly appreciates that individual facts can support multiple interpretations and can speak to a number of different truths when the relationships between the records are manipulated and utilised as evidence in an argument. The faith that archival theory places in concepts such as original order and the archival bond reveals a firm belief that "knowledge about a past to which there was no direct access [can], nevertheless, be attained by examining its' documentary traces." 35 Ultimately, it is knowledge of the past that is offered by archival documents, not the truth. It is possible to know the intention and meaning of the archival document in its operation in the environment of its creation, just as it is possible for the individual to remember broad contours of their past. The intentions and meanings of the author are not always discernable and, therefore, the specificity of the rationale behind the action is often lost and cannot be verified; but that the action actually occurred can be verified and attested to by the document.

\section{Remembering and Forgetting}

If imagination is capable of intruding upon memory in order to embellish or alter past perceptions of reality, if it is capable of transmitting untruths, is it not also capable of extinguishing the memory completely? It is unclear whether forgetting is an attribute of imagination acting upon memory, an inherent part of memory itself, or an entirely new process or exercise of the mind. In any case, it is an accepted truism that an individual will likely forget more than they will ever remember.

Forgetting is an important discriminating function. Without the ability to forget, memory would amount to chaos and a multiplicity of impressions about the past 
would overwhelm everyday experience. Numerous clinical studies have been developed to explain the different modes in which individuals perform this task. The various reasons and rationales for forgetting are as unstable as those for remembering. Some experiences are forgotten because they are painful or embarrassing, sometimes an individual must forget in order to contend with a changing world, and sometimes experiences do not contain particular meaning and simply slip our minds. Clinically defined, forgetting may be intentional, directed or unnoticed respectively. ${ }^{36}$

In the individual mind there are two general methods for forgetting. "Lack of rehearsal" or suppression, is a practice of restraint employed by the conscious mind to avoid thinking of a past experience. If a mildly painful or uncomfortable experience has occurred then the individual makes a conscious choice not to recall the incident. If and/or when a memory of the experience is recalled, through some form of stimulus, it is pushed back. In so doing the individual "reduces the likelihood that the suppressed experiences spontaneously spring to mind." 37

The second method of forgetting is based on the theory that the brain works to protect the individual against extremely emotionally damaging experiences through the mechanism of repression. These experiences are perhaps too staggering for the conscious mind to handle and therefore can be forgotten almost as soon as they occur.

According to some therapists, repression is powerful enough to block out horrifying months and years of sexual abuse, rape, even ritualistic torture... [however] the repressed memories are not lost forever; they are thought to percolate in a remote corner of the unconscious, causing various problems and symptoms. ${ }^{38}$

It is crucial to establish that remembering and forgetting go hand in hand. Forgetting is an important discriminating factor and essential to successful remembering, they are complementary processes which aid in maintaining the overall functionality of the mind. The act of forgetting, except in certain cases of traumatic experience or disease, is not a failing of memory, but a condition of its health and life; it is an adaptive feature of our memories. If each and every detail of an experience were remembered, it would be impossible to form a cohesive whole, from which meaning could be elicited. Forgetting memories over time is "an economical response to the demands placed on memory by the environment in which we live." 39

The central difference between remembering and forgetting comes not in their practice, but in the moment they are no longer practiced. It may seem overly simplistic, but once the individual dies, the memories of their experiences, however faulty, may remain with others through an oral act or transcription. What has been forgotten however, disappears forever, no longer present in the individual or collective unconscious mind.

Archives have often been charged with neglect for the amount of material that does not find its way into the canon of the official past; for in this neglect, documentary traces of the past are destined to be forgotten. Archives are also accused of being agents of the established state; politicized actors on the national stage. To some extent this is 
true, as archives are obliged to serve the information needs of their sponsoring agency. This accusation is particularly pointed when addressed to institutions that are meant to serve the information and memory needs of a large community, such as a nation-state. How is it possible to include all of the information that bears relevance to each of the smaller juridical communities that participate in this larger construct? Archivists have come to admit that, in fact, it is not possible.

The collective memory stored in archives is also subject to forgetfulness. Like the memory of the individual, certain things must be forgotten in order to provide space (often quite literally) for other memories to be retained. In the interest of meaning and cohesion, all experiences cannot be remembered, and in the scenario of the archival institution, this means that all memories cannot be preserved. As with individual memory, the best that can be expected is a representation of the general contours of the past is retained where the specificities are often lost.

Carolyn Steedman, in her article The Space of Memory in an Archive states

The Archive is not potentially made up of everything, as is human memory; and it is not the fathomless and timeless place in which nothing goes away, as is the unconscious. ${ }^{40}$

Steedman's point, that there is no unconscious memory in the archives, is not necessarily correct for the memory that exists in archives often has an unconscious quality to it. Like the unconscious memory of the individual, it is merely waiting for elicitation - the correct cue to bring it forth. It is not the responsibility or role of the archives to provide these cues that unlock forgotten memories - that is the role of the researcher.

One example will serve to illustrate this point about unconscious memory and archives. Timothy J. Gilfoyle's article, entitled "Prostitutes in the Archives: Problems and Possibilities in Documenting the History of Sexuality" demonstrates how archives, particularly in North America, have not consciously attempted to document the history of prostitution in order to bring it into the fold of the collective memory. The subject area of sexuality has not always been located within the perceived boundaries of the conscious memory of the collective society or national identity. It is only with the advent of "social history" that it has become a topic of interest to a great many researchers. Archivists did not anticipate or plan for research into the history of sexuality, and yet the memory exists in the documentary heritage of the archives.

As Gilfoyle points out, it is through the retention of seemingly unrelated court documents that the history of sexuality has remained a part of the collective memory.

Sodomy indictments, for example, reveal the advent and possible formation of a male homosexual community. Bail bonds for arrested prostitutes can illustrate levels of community support of the network of pimps. Libel suits against various editors mark the earliest attacks on obscenity and the beginnings of the pornography industry. ${ }^{41}$ 
All of these activities remain buried in the unconscious memory of the archival document, waiting to be summoned forth by the industrious researcher who, like a good therapist, utilises the appropriate cues to bring forth the memory. This is not to say that there is no room for improvement in the appraisal and selection of the documentary evidence of the collective memory. But where gaps and silences exist, the resonance of an echo can be heard, revealing a certain amount of knowledge about the past yet again.

\section{Conclusion}

The juxtaposition of collective memory with that of the individual gives credence to the metaphor of archives and archivists as keepers of the past. While the obvious similarities are apparent from the outset, they appear to only be strengthened upon closer examination. Both collective memory and individual memory operate by recalling experiences through the mechanisms of conscious and habit memory; both employ forgetfulness for the management of experiences which are not imbued with relevant meaning; both utilise memory in their formation and designation of identity; and both have a tenuous relationship with truth.

However, it is necessary to realize that merely because the metaphor rings true, it nevertheless needs to be constantly reassessed. If archives are to amass and represent the memories of the society, which they serve, they must remain closely linked to the political, academic, cultural and economic trends which help to define the identity of that society. Archivists must attend to the lessons learned from individual memory and its processes. Society and its collective identity and memory are constantly evolving through new combinations of individuals, juridical bodies, the past, the present and hopes for the future. Ultimately, the question of whether memory is more of a curse than a cure must be left to individual interpretation and the shifting meanings that are constantly and alterably attached to it.

\section{Notes}

I Kenneth E. Foote, “To Remember and Forget: Archives, Memory and Culture”, American Archivist 53 (Summer 1990): 380.

2 Gary Taylor, Cultural Selection (New York: Harper \& Collins, I996), I42.

3 Hans Booms, "Society and the Formation of a Documentary Heritage: Issues in the Appraisal of Archival Sources," Archivaria 24 (Summer 1987): 73.

4 In Connerton, 36.

5 In Foote: 379.

6 Mark Kingwell, Practical Judgments: Essays in Culture, Politics, and Interpretation (Toronto:

University of Toronto Press, 2002), 277.

7 Steven Rose, "The Making of Memory," in The Anatomy of Memory: An Anthology, ed. James

McConkey (New York: Oxford University Press, 1996), 57.

8 Mary Warnock, Memory (London: faber and faber, 1987), 9.

9 Allan Megill, "History, memory, identity," History of the Human Sciences II, No.4 (I998): 42. 
Io This definition of the archival document is the basis of the archival fonds, which is constituted by the whole of the documents created and received by the juridical or physical person.

II Richard Brown, "Records Acquisition Strategy and its Theoretical Foundation," Archivaria 33 (Winter 199I-92): 38 .

I2 In Connerton, 38.

I3 Richard Harvey Brown and Beth Davis-Brown, "The making of memory: the politics of archives, libraries and museums in the construction of the national consciousness," History of the Human Sciences II, No.4 (1998): 19.

I4 Ian Wilson, "A Noble Dream: The Origins of the Public Archives of Canada," Archivaria I5 (Winter 1982-1983): 28.

I5 Shirley Spragge, "The Abdication Crisis: Are Archivists Giving Up Their Cultural

Responsibility?," Archivaria 40 (Summer 1996):I73.

Is Paul Connerton, How Societies Remember (Cambridge: Cambridge University Press, 1989), 2.

I6 Walter W. Menninger, "Memory and History: What Can You Believe," American Archivist 57, No.3 (Summer 1994): 97.

I7 Menninger: 99.

I8 in Foote: 379

I9 Helen Samuels, "Improving Our Disposition: Documentation Strategy," Archivaria 33 (Winter 199I-92): I33.

20 Brien Brothman, "Orders of Value: Probing the Theoretical Terms of Archival Practice," Archivaria 32 (Summer 199I): 86.

2I Terry Eastwood, "Towards a Social Theory of Appraisal," in The Archival Imagination: Essays in Honour of Hugh A. Taylor, ed. Barbara L. Craig (Ottawa: Association of Canadian Archivists, 1992), 76.

22 Webster's New Complete Dictionary, 1995 ed., s.v. "imagination.”

23 Warnock, 36.

24 Daniel L. Schacter, Searching for Memory: The Brain, the Mind and the Past (New York: Basic Books, 1996), 93.

25 Schacter, 5 .

26 Warnock, 2I.

27 Warnock, 25 .

28 Menninger: IoI.

29 Toni Morrison, “Memory, Creation and Writing,' in The Anatomy of Memory: An Anthology, ed. James McConkey (New York: Oxford University Press, 1996), 213.

30 Michel Foucault, The Archaeology of Knowledge (New York: Harper Colophon Books, 1972), 6.

3I Keith Jenkins, Rethinking History (New York: Routledge, I99I), 47.

32 Heather MacNeil, "Trusting Records: The evolution of Legal, Historical and Diplomatic Methods of Assessing the Trustworthiness of Records, from Antiquity to the Digital Age" (Ph.D. diss., University of British Columbia, 1998), 136.

33 Foucault, 7.

34 MacNeil, 3I.

35 Elizabeth Ligon Bjork, Robert A. Bjork and Michael Anderson, "Varieties of goal-directed forgetting" in Intentional Forgetting, eds. Jonathan M. Golding and Colin M. MacCleod (Mahwah: Lawrence Erlbaum Associates, 1998), I03.

36 Schacter, 254 . 
37 Schacter, 255 .

38 Schacter, 8I.

39 Carolyn Steedman, "The Space of Memory in Archives," History of the Human Sciences II, No. 4 (1998): 67.

40 Timothy J. Gilfoyle, "Prostitutes in the Archives: Problems and Possibilities in

Documenting the History of Sexuality," American Archivist 57, No. 3 (Summer 1994): 520.

\section{Bibliography}

Bjork, Elizabeth Ligon; Bjork, Robert A.; and Anderson, Michael. "Varieties of goal-directed forgetting." in Intentional Forgetting, eds. Jonathan M. Golding and Colin M. MacCleod, I03-I37. Mahwah: Lawrence Erlbaum Associates, 1998.

Booms, Hans. "Society and the Formation of a Documentary Heritage: Issues in the Appraisal of Archival Sources." Archivaria 24 (Summer 1987): 69-107.

Brothman, Brian. "Orders of Value: Probing the Theoretical Terms of Archival Practice." Archivaria 32 (summer 199I): 7I-95.

Brown, Richard Harvey, and Beth Davis-Brown. "The Making of Memory: the Politics of Archives, Libraries and Museums in the Construction of the National Consciousness." History of the Human Sciences II, No. 4 (1998): 17-32.

Burke, Peter. History and social theory. Cambridge: Polity Press, 1992.

Connerton, Paul. How Societies Remember. Cambridge: Cambridge University Press, 1989.

Cook, Terry. "Mind Over Matter: Towards a New Theory of Archival Appraisal." in The archival Imagination: Essays in Honour of Hugh A. Taylor, ed. Barbara Craig, 38-70. Ottawa: Association of Canadian Archivists, 1992.

Egerton, George, ed. Political Memoir: Essays on the Politics of Memory. London, England: F. Cass, 1994.

Eastwood, Terry. "Towards a Social Theory of Appraisal." in The Archival Imagination: Essays in Honour of Hugh A. Taylor, ed. Barbara Craig, 71-89. Ottawa: Association of Canadian Archivists, I992.

Foote, Kenneth E. “To Remember and Forget: Archives, Memory and Culture." American Archivist 53 (Summer 1990): 378-392.

Foucault, Michel. The Archaeology of Knowledge. New York: Harper Colophon Books, 1972.

Gilfoyle, Timothy J. "Prostitutes in the Archives: Problems and Possibilities in Documenting the History of Sexuality." American Archivist 57, No. 3 (1994): 514-527.

Jenkins, Keith. Rethinking History. New York: Routledge, I991.

Kingwell, Mark. Practical Judgments: Essays in Culture, Politics and Interpretation. Toronto: University of Toronto Press, 2002.

MacNeil, Heather. "Trusting Records: The Evolution of Legal, Historical and Diplomatic Methods of Assessing the Trustworthiness of Records, from Antiquity to the Digital Age." Ph.D. diss, School of Library and Archival Studies, University of British Columbia, I998.

Megill, Allan.” History, memory, identity." History of the Human Sciences II, No. 4 (1998): 37-62.

Menninger, Walter W. "Memory and History: What Can You Believe." Archival Issues 2I, no. 2 (1996): 97-106.

Morrison, Toni. "Memory, Creation and Writing." in The Anatomy of Memory: An Anthology, ed. James McConkey, 212-218. New York: Oxford University Press, 1996.

Rose, Steven. "The Making of Memory." in The Anatomy of Memory: An Anthology, ed. James McConkey, 55-59. New York: Oxford University Press, 1996.

Samuels, Helen. "Improving Our Disposition: Documentation Strategies." Archivaria 33 (Winter 1991-92): I25-I40.

Schacter, Daniel L. Searching for Memory: The Brain, the Mind and the Past. New York: Basic Books, 1996. 


\section{Encounters/Encuentros/Rencontres}

Spragge, Shirley. "The Abdication Crisis: Are Archivists Giving Up Their Cultural Responsibility?" Archivaria 40 (Summer 1996): 173-18I.

Steedman, Carolyn. "The Space of Memory in Archives," History of the Human Sciences II, No. 4 (1998): 65-84.

Taylor, Gary. Cultural Selection. New York: Harper \& Collins, 1996.

Warnock, Mary. Memory. London: faber and faber, 1987.

Wilson, Ian. "A Noble Dream: The Origins of the Public Archives of Canada." Archivaria Is (Winter 1982-83): 27-35.

Zajko, Vanda. "Myth as archive." History of the Human Sciences II, No. 4 (1998):I03-II9. 